$9-2020$

\title{
Localizing an occult insulinoma by selective calcium arterial stimulation test: First ever experience and a new dimension to diagnosis in Pakistan
}

Muhammad Owais Rashid

Sumerah Jabeen

Zareen Kiran,

Khurram Minhas

Muhammad Azeemuddin

See next page for additional authors

Follow this and additional works at: https://ecommons.aku.edu/

pakistan_fhs_mc_med_diabet_endocrinol_metab

Part of the Endocrine System Diseases Commons, Endocrinology, Diabetes, and Metabolism Commons, Pathology Commons, and the Radiology Commons 
Authors

Muhammad Owais Rashid; Sumerah Jabeen; Zareen Kiran,; Khurram Minhas; Muhammad Azeemuddin; and Najmul Islam 
Localizing an occult insulinoma by selective calcium arterial stimulation test: first ever experience and a new dimension to diagnosis in Pakistan

Muhammad Owais Rashid1', Sumerah Jabeen², Zareen Kiran³, Muhammad Khurram Minhas4, Muhammad Azeem5, Najmul Islam6

\begin{abstract}
Insulinomas are rare, usually benign, solitary tumours accounting for $60 \%$ of islet cell tumours. These tumours can be difficult to localize preoperatively due to their small size. We present a challenging case of a 40 year old male with frequent hypoglycaemic spells and endogenous hypoglycaemia who presented as a diagnostic dilemma. Patient had an occult insulinoma with inconclusive CT Abdomen, MRI Abdomen and Octreotide scan. The final localization of the tumour was made by selective arterial calcium stimulation testing (SCAT), done for the first time in Pakistan at Aga Khan University Hospital. This was followed by successful distal pancreatectomy as localizd by SACT yielding a well differentiated neuroendocrine tumour. After surgery patient made a robust recovery with no further hypoglycaemic symptoms. Hence successful localization and management of occult insulinomas can be challenging but can be achieved with the advent of newer invasive modalities.
\end{abstract}

Keywords: Insulinomas, Hypoglycemia, Neuroendocrine tumour

DOI: https://doi.org/10.5455/JPMA.19325

\section{Introduction}

The first insulinoma was described by an orthopaedic surgeon, Wider and colleagues in 1927, who experienced frequent neuroglycopenic symptoms due to prolonged fasting in the operating room. ${ }^{1}$ Insulinomas are rare tumours with an incidence of 4 patients per 1 million /year and accounts for $60 \%$ of islet cell tumours. ${ }^{2}$ They are typically solitary tumours with $90 \%$ measuring less than 2 $\mathrm{cm}$. They can also present as a benign multicentric disease in patients with MEN 1.3 Due to their nonspecific, occasionally bizarre symptoms these tumours can disguise themselves with various neuropsychiatric conditions. ${ }^{4} \mathrm{An}$ occult insulinoma refers to a biochemically proven tumour with an undetermined anatomical site before surgery. ${ }^{5}$ Their small size and difficult preoperative localization along 1 Department of Endocrinology, The Indus Hospital, Karachi, Pakistan; 2,3,6Department of Endocrinology, Aga Khan University Hospital, Karachi, Pakistan; 4Department of Histopathology, Aga Khan University Hospital, Karachi, Pakistan; ${ }^{5}$ Department of Rabiology, Aga Khan University Hospital, Karachi, Pakistan

Correspondence: Sumerah Jabeen. e-mail: sumerahjabeen@hotmail.com with nonspecific symptoms poses a diagnostic dilemma to both the endocrinologists and surgeons. We present a case of a 40 year old male with an occult insulinoma which after a rigorous but futile imaging work up was finally localized by Selective Calcium Arterial Stimulation Testing (SCAST), done first time in the history of Pakistan at Aga Khan University Hospital. The consent of the patient was taken prior to the manuscript writing.

\section{Case}

A 44 years old male known case of Hypothyroidism and Hypertension presented to our endocrine clinic for the first time in June 2017 with episodes of recurrent sweating, tremors, palpitations and generalized weakness. Patient had these symptoms since last 2 years, observed during fasting and relieved with food intake. During these episodes his glucose went down to $35-40 \mathrm{mg} / \mathrm{dl}$. He combated with these spells of hypoglycaemia with instant intake of choclates or sugar but did not seek any professional help, due to excessive binge eating there was a noticeable weight gain over this two year period. He had a past history of pulmonary tuberculosis, treated few years back. Family history was positive for diabetes, hypertension, coronary artery disease and breast carcinoma. His medication history included Olmesartan 40 $\mathrm{mg} O D$ and thyroxine $150 \mathrm{mcg} O \mathrm{OD}$. His multiple Serum insulin, C- peptide, blood glucose done during 2 years period were clearly suggestive of endogenous hypoglycaemia. Patient had a BMl of $31.5 \mathrm{~kg} / \mathrm{m}^{2}$. Rest of his physical examination was unremarkable. On the basis of history and biochemical evaluation diagnosis of Spontaneous hypoglycaemia secondary to endogenous hyperinsulinaemic hypoglycaemia was made and patient was advised CT scan abdomen (Pancreatic protocol) which showed no pancreatic mass following which he was asked to get MRI abdomen as next line investigation which also did not reveal any pancreatic, hepatic or other masses. He then underwent Somatostatin receptor scintigraphy with no uptake in pancreas or liver. Patient was then planned for Angiography of Coeliac and Superior mesenteric arteries to look for tumour blush followed by Selective Calcium Arterial Stimulation Testing (SCAST). This test involved the femoral vein and artery cannulation with passage of a sampling catheter to the right hepatic vein for sampling of insulin and sequentially under fluoroscopic guidance, a 
Table: Selective Calcium Arterial Stimulation Test Results.

\begin{tabular}{|c|c|c|c|c|}
\hline $\begin{array}{l}\text { Peripheral } \\
\text { Artery }\end{array}$ & $\begin{array}{l}\text { Hepatic } \\
\text { Artery }\end{array}$ & $\begin{array}{c}\text { Superior Mesenteric } \\
\text { Artery }\end{array}$ & $\begin{array}{c}\text { Gastroduodenal } \\
\text { Artery }\end{array}$ & $\begin{array}{l}\text { Splenic } \\
\text { Artery }\end{array}$ \\
\hline \multicolumn{5}{|l|}{0 sec: } \\
\hline Preinjection & Post $30 \mathrm{sec}$ & Post $30 \mathrm{sec}$ & Post $30 \mathrm{sec}$ & Post $30 \mathrm{sec}$ \\
\hline Insulin 51.30 & Insulin 48.80 & Insulin 127.60 & Insulin 139.10 & Insulin >300 \\
\hline \multirow[t]{13}{*}{ C-peptide 7.32} & C-peptide 6.13 & C-peptide 9.06 & C-peptide 12.90 & C-peptide $>20$ \\
\hline & Post $60 \mathrm{sec}$ & Post $60 \mathrm{sec}$ & Post $60 \mathrm{sec}$ & Post $60 \mathrm{sec}$ \\
\hline & Insulin 55.30 & Insulin 114.20 & Insulin 144.00 & Insulin >300 \\
\hline & C-peptide 6.73 & C-peptide 9.68 & C-peptide 9.46 & C-peptide 17.50 \\
\hline & Post $90 \mathrm{sec}$ & Post $90 \mathrm{sec}$ & Post $90 \mathrm{sec}$ & Post $90 \mathrm{sec}$ \\
\hline & Insulin 63.40 & Insulin 137.30 & Insulin 127.60 & Insulin >300 \\
\hline & C-peptide 7.29 & C-peptide 9.17 & C-peptide10.50 & C-peptide 12.30 \\
\hline & Post $120 \mathrm{sec}$ & Post $120 \mathrm{sec}$ & Post $120 \mathrm{sec}$ & Post $120 \mathrm{sec}$ \\
\hline & Insulin 63.40 & Insulin 128.10 & Insulin 51.30 & Insulin 214.60 \\
\hline & C-peptide 6.39 & C-peptide 9.99 & C-peptide 7.32 & C-peptide 12.70 \\
\hline & Post $180 \mathrm{sec}$ & Post 180 sec & Post $180 \mathrm{sec}$ & Post $180 \mathrm{sec}$ \\
\hline & Insulin 59.80 & Insulin 105.80 & Insulin 139.80 & Insulin 149.80 \\
\hline & C-peptide 7.83 & (-peptide 10.00 & C-peptide 11.10 & C-peptide 12.20 \\
\hline
\end{tabular}

catheter placed into the splenic, superior mesenteric and gastroduodenal arteries to allow injection of calcium gluconate into these arteries. A positive response was defined as at least a doubling of the insulin level after injection calcium gluconate at more than one time point.

SCAST with venous sampling after calcium infusion showed many folds increase in insulin, C peptide levels in the splenic artery thus pointing towards the culprit lesion in the body or tail of his pancreas (Table). Patient was then referred to an experienced surgeon with the plan of a pancreactic enucleation if the tumour could be localized on peroperative ultrasound otherwise distal pancreactomy being the second option. As the adenoma could not be localized on peroperative ultrasound therefore he

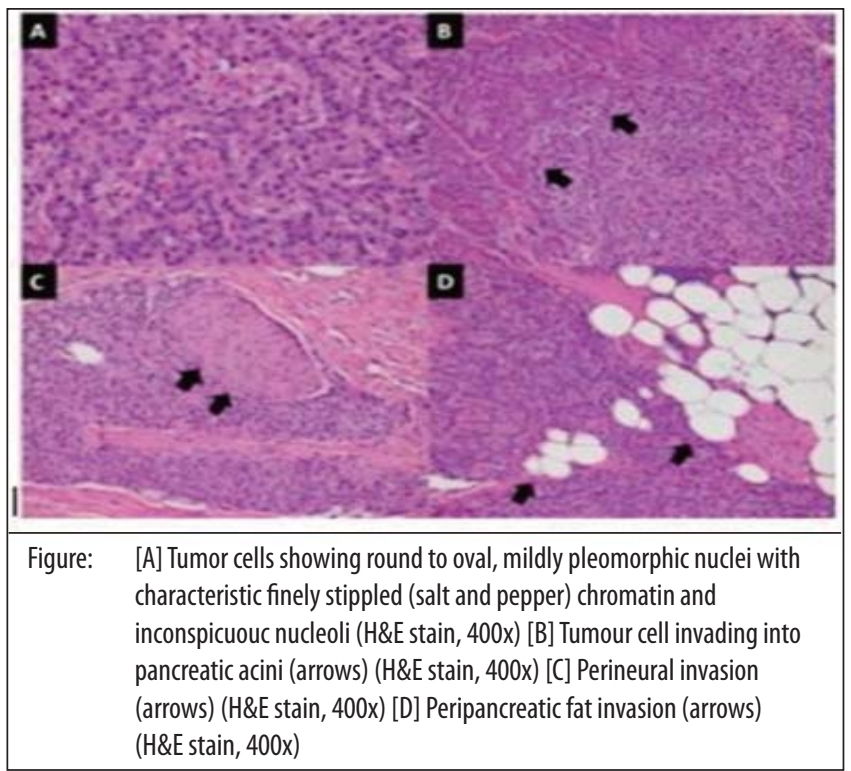

underwent distal pancreatectomy. His histopathology report showed a well differentiated neuroendocrine tumour, grade 1 of distal pancreas with a size of $1.5 \times 1.3$ $\mathrm{cm}, \mathrm{Ki}-67$ index of $<2 \%$ and stage of pT1,Nx (figure). Postoperatively patient made good recovery with no further hypoglycaemic episodes on follow up after one month of his surgery and to date enjoying a healthy life.

Patient was not evaluated for MEN1 as he denied any other symptoms besides hypoglycaemia, also his baseline work up did not show any clue of a concomitant illness.

\section{Discussion}

Insulinomas are rare tumours but among the functioning islet cell tumours are the most common. Patients usually present with fasting hypoglycaemia but upto $25 \%$ of such patients can also present with post prandial hypoglycaemia. The hypoglycaemic spells constitute both neuroglycopenic symptoms including confusion, visual change and unusual behaviour that may or may not be preceded by sympathoadrenal symptoms which includes tremulousness, palpitations or diaphoresis.6,7 The hypoglycaemia in insulinoma is observed to be due to reduced hepatic glucose output rather than an increased glucose utilization. In a study conducted at Mayo clinic it was observed that it took a median time of 1.5 years for a patient to report his symptoms before a diagnosis of insulinoma was made. ${ }^{2}$

The biochemical diagnosis of insulinoma is established by demonstrating raised serum insulin and C- peptide levels during an episode of hypoglycaemia, but the diagnosis and preoperative localization of these occult tumours is never straight forward owing to the small size and sporadic distribution, thus it remains a diagnostic challenge to the endocrinologists, surgeons and the radiologists. Surgical removal is the treatment of choice in insulinomas, therefore it is imperative to localize these tumours preoperatively as it not only helps in deciding the type of surgery but also some of these tumours may not be palpable at the time of surgery.

After biochemical confirmation preoperative procedures for tumour localization includes number of noninvasive and invasive radiological investigations most of which are operator dependent and require skills. These include transabdominal ultrasonography (sensitivity 30\%-61\%), CT (sensitivity 42\%-78\%), MRI Abdomen (sensitivity 20\%$100 \%$ ), octreotide scan (sensitivity $78 \%-86 \%$ ), Endoscopic ultrasonography (sensitivity 80\%), Selective Arterial Calcium Stimulation Testing(SACST) with hepatic venous sampling(sensitivity 90\%), and intraoperative 
ultrasonography (sensitivity 90\%) with bimanual palpation. 8

Selective Arterial Calcium Stimulation Testing (SACST) is an interventional radiological technique. John L. Doppman ${ }^{9}$ developed SACST after observing that intravenously administered calcium stimulates insulin release from from insulinoma, but not from normal beta cells. Placzkowski et al. demonstrated a sensitivity for localization of upto $93 \%$ in patients who underwent this procedure in Mayo clinic series. 6

Literature review shows SACT to be superior to other non invasive modalities with localization sensitivity of 87.5 to $90 \% .{ }^{10}$ When compared with other invasive techniques like EUS, the localization sensitivity of EUS is similar to SACT but does not provide functional information with its specificity being affected when pancreatic nodularities are mistaken for insulinomas. The short comings of the two procedures are similar including invasiveness with lack of universal availability and operator and centre dependence. ${ }^{11}$

SACT involves the arterial catheterization of arteries supplying the pancreas and injecting calcium gluconate which acts as the insulin secretagogue. The samples are then collected from the right hepatic vein before and after the calcium gluconate injection at different time intervals. The pancreatic artery showing the highest relative fold increase (two to four times) in hepatic venous insulin concentration over baseline following calcium stimulation is considered to be the dominant artery supplying the insulinoma. ${ }^{9}$ Preoperative localization of insulinoma can guide the surgeon to decide the extent of surgery.

Since we did not have the availability of Endoscopic ultrasound facility in our center therefore Selective Arterial calcium Stimulation testing with hepatic venous sampling was considered an option for tumour localization .

Despite its high sensitivity, the utility of SACT outside insulinoma diagnosis remains unkown. Similarly the diagnostic accuracy of this test also remains undetermined as this test is done on patients with a pre established diagnosis of insulinoma. The diagnostic accuracy of SACT was questioned with diffusely positive SACT response in cases of surreptious Repaglinide and sulfonylurea. ${ }^{12,13}$

Important challenge in doing SCAST is having a centre equipped with interventional radiology services with Interventional radiologist able to interpret normal and abberant vascular anatomy since the anatomy of the coeliac axis and superior mesenteric artery is aberrant in approximately 40 percent of patients. Close communication between the endocrinologist, interventional radiologist and laboratory is required to interpret the results correctly and manage the patient appropriately.

Although being done in different countries this test was a new milestone in the endocrine history of Pakistan as it was the first time ever that this invasive technique was successfully attempted. Localizing the culprit insulin producing tumour by SACST open new doors, providing ground for other centers in Pakistan equipped with interventional radiology to start performing this test where diagnosing insulinoma remains a challenge pre operatively.

\section{Conclusion}

Insulinomas being rare intrapancreatic tumours can pose a diagnostic dilemma due to its difficult preoperative localization but with the advent of newer invasive modalities there has been a good yield in localizing them preoperatively and thus avoiding unnecessary total pancreatectomy.

Disclaimer: None to declare.

Conflict of Interest: None to declare.

Funding Sources: None to declare.

\section{References}

1. Grant C. Insulinoma. Best Pract Res Clin Gastroenterol. 2005; 19:78398.

2. Service $F$, Mcmahon $M$, O'Brien $P$, Ballard D. Functioning Insulinoma-Incidence, Recurrence, and Long-Term Survival of Patients: A 60-Year Study. Mayo Clinic Proceedings. 1991; 66:711-9.

3. Patel S, Narwari M, Parekh D, Shah V. Insulinoma: case report and review of diagnostic and treatment modalities. J Assoc Physicians India. 2013; 61:423-6.

4. Rehman A. Insulinoma--a deceptive endocrine tumour. J Pak Med Assoc. 2011; 61:911-4.

5. Abboud B. Occult sporadic insulinoma: Localization and surgical strategy. World J Gastroenterol. 2008; 14:657-65.

6. Placzkowski K, Vella A, Thompson G, Grant C, Reading C, Charboneau J, et al. Secular Trends in the Presentation and Management of Functioning Insulinoma at the Mayo Clinic, 1987-2007. J Clin Endocrinol Metab. 2009; 94:1069-73.

7. Tarchouli M, Ait Ali A, Ratbi M, Belhamidi M, Essarghini M, Aboulfeth $E$, et al. Long-standing insulinoma: two case reports and review of the literature. BMC Research Notes. 2015; 8:444

8. Wass J, Owen K, Turner H. Oxford handbook of endocrinology and diabetes.3rd Edition. United Kingdom: Oxford University Press 2014. 563.

9. Doppman JL, Miller DL, Chang R, Shawker TH, Gorden P, Norton JA. Insulinomas: localization with selective intraarterial injection of calcium. Radiology. 1991; 178:237-41.

10. Perkov D, Novosel L, Baretić M, Kastelan D, Smiljanic R, Padovan RS. LOCALIZATION OF PANCREATIC INSULINOMAS WITH ARTERIAL STIMULATION BY CALCIUM AND HEPATIC VENOUS SAMPLING-PRESENTATION OF A SINGLE CENTRE EXPERIENCE. Acta Endocrinol (Buchar). 2016; 12:55-62.

11. Guettier JM, Kam A, Chang R, Skarulis MC, Cochran C, Alexander HR, et al. Localization of insulinomas to regions of the pancreas by intraarterial calcium stimulation: the NIH experience. J Clin Endocrinol Metab. 2009; 94:1074-80. 
12. Hirshberg B, Skarulis MC, Pucino F, Csako G, Brennan R, Gorden P. Repaglinide-induced factitious hypoglycemia. J Clin Endocrinol Metab. 2001; 86:475-7.
13. Manning PJ, Espiner EA, Yoon K, Drury PL, Holdaway IM, Bowers A. An unusual cause of hyperinsulinaemic hypoglycaemia syndrome. Diabet Med. 2003; 20:772-6 